\title{
Evidence for terrane boundaries and suture zones across Southern Mongolia detected with a 2-dimensional magnetotelluric transect
}

\author{
Matthew J. Comeau ${ }^{* *}\left(\mathbb{0}\right.$, Michael Becken ${ }^{1}$, Johannes S. Käufl', Alexander V. Grayver², Alexey V. Kuvshinov², \\ Shoovdor Tserendug ${ }^{3}$, Erdenechimeg Batmagnai ${ }^{2}$ and Sodnomsambuu Demberel ${ }^{3}$
}

\begin{abstract}
Southern Mongolia is part of the Central Asian Orogenic Belt, the origin and evolution of which is not fully known and is often debated. It is composed of several east-west trending lithostratigraphic domains that are attributed to an assemblage of accreted terranes or tectonic zones. This is in contrast to Central Mongolia, which is dominated by a cratonic block in the Hangai region. Terranes are typically bounded by suture zones that are expected to be deepreaching, but may be difficult to identify based on observable surface fault traces alone. Thus, attempts to match lithostratigraphic domains to surface faulting have revealed some disagreements in the positions of suspected terranes. Furthermore, the subsurface structure of this region remains relatively unknown. Therefore, high-resolution geophysical data are required to determine the locations of terrane boundaries. Magnetotelluric data and telluric-only data were acquired across Southern Mongolia on a profile along a longitude of approximately $100.5^{\circ} \mathrm{E}$. The profile extends $\sim 350 \mathrm{~km}$ from the Hangai Mountains, across the Gobi-Altai Mountains, to the China-Mongolia border. The data were used to generate an electrical resistivity model of the crust and upper mantle, presented here, that can contribute to the understanding of the structure of this region, and of the evolution of the Central Asian Orogenic Belt. The resistivity model shows a generally resistive upper crust $(0-20 \mathrm{~km})$ with several anomalously conductive features that are believed to indicate suture zones and the boundaries of tectonic zones. Moreover, their spatial distribution is coincident with known surface fault segments and active seismicity. The lower crust (30-45 km) becomes generally less resistive, but contains an anomalously conductive feature below the Gobi-Altai zone. This potentially agrees with studies that have argued for an allochthonous lower crust below this region that has been relaminated and metamorphosed. Furthermore, there is a large contrast in the electrical properties between identified tectonic zones, due to their unique tectonic histories. Although penetration to greater depths is limited, the magnetotelluric data indicate a thick lithosphere below Southern Mongolia, in contrast to the previously reported thin lithosphere below Central Mongolia.
\end{abstract}

Keywords: Magnetotellurics, Electrical resistivity, Southern Mongolia, Gobi, Terranes, Suture zones

\section{Introduction}

Mongolia is a part of the Central Asian Orogenic Belt $(\mathrm{CAOB})$, an accretionary orogeny that covers a large area of Central and Eastern Asia bounded to the north

\footnotetext{
*Correspondence: matthew.comeau@uni-muenster.de

${ }^{1}$ Institut für Geophysik, Universität Münster, Corrensstrasse 24,

48149 Münster, Germany

Full list of author information is available at the end of the article
}

by the Siberian craton and to the south by the North China (Sino-Korean) and Tarim cratons (e.g., Yin 2010). The origin and evolution of the $\mathrm{CAOB}$ is not well known and remains controversial, however the geological structure is known to be a combination of microcontinents and mobile belts (e.g., Kovach et al. 2013). Central Mongolia is dominated by the Hangai block, which is part of the Hangai Dome intraplate plateau, and other 
continental fragments, including the Baydrag block, which are believed to be composed of Precambrian basement rocks (Badarch et al. 2002; Cunningham 2001). In contrast, geological studies have revealed that Southern Mongolia is composed of an accretionary collage of many (nine or more) lithologically and structurally distinct domains (Badarch et al. 2002). These east-west trending lithostratigraphic provinces consist of back-arcs, forearcs, island-arcs, and accretionary wedges that surround the central Hangai nucleus. The distinct lithostratigraphic domains are attributed to separately accreted terranes (Badarch et al. 2002) or to larger lithotectonic blocks (Kröner et al. 2010). Kröner et al. (2010) simplified this area into four principal tectonic zones, generally aligned with major known fault zones. These are, from north to south: the Lake Zone, the Gobi-Altai Zone, the Trans-Altai Zone, and the South-Gobi Zone (Fig. 1). The inferred geological history and composition of these regions is summarized in a following section. The tectonic history of this region is complex, and includes several subduction events (Yin 2010; Jiang et al. 2017; Xiao et al. 2015) and the Mesozoic closure of the MongolOkhotsk ocean (e.g., Van der Voo et al. 2015).

Terranes are defined as fault-bounded fragments whose surface geology differs from that of adjacent areas (e.g., Badarch et al. 2002; Kröner et al. 2010). However, attempts to match lithostratigraphic domains to surface faulting (using geochronology, structural constraints, and aerial potential field measurements) have revealed some disagreements in the positions of suspected terranes (e.g., Badarch et al. 2002; Kröner et al. 2010; Guy et al. 2014). Geophysical potential field data (gravity and magnetics) are useful to distinguish lithostratigraphic domains because gravity and magnetic signals depend on the specific petrophysical properties of the rock components (that is, density and magnetic susceptibility). However, the main challenge with potential field data is to accurately interpret the depth of each feature. In fact, potential field data have shown close agreement with the four principal tectonic zones (Guy et al. 2014). Unfortunately, this region lacks seismic data, which could provide new evidence for lithospheric structure.

Instead of identifying terranes by the distinguishable variations in crustal properties between them, due to their unique petrophysical properties and rock types, they can instead be identified by their boundaries, which are rheological weak zones between them. As mentioned above, if the contrasting lithostratigraphic domains represent distinct terranes they should be partitioned and bounded by faults and suture zones that are suspected to be crustal or lithospheric-scale (e.g., Badarch et al. 2002; Calais et al. 2003). However, due to the extended intracontinental convergent deformation in this region, these faults and suture zones may be very narrow zones, or covered at the surface, and thus difficult to detect (e.g., Dewey 1977). Hence geophysical methods that can accurately image deep crustal structures are required.

Magnetotelluric (MT) data image subsurface electrical resistivity using natural electromagnetic signals measured over a broad range of frequencies (e.g., Chave and Jones 2012). The resistivity of a rock is a unique geophysical signature, which can vary over several orders of magnitude, and is especially sensitive to the quantity and composition of crustal fluids and partial melt. Because faults and suture zones are regions of fractured, weakened crust, due to past and present deformation, they often have circulating fluids that act to decrease their electrical resistivity (e.g., Türkoğlu et al. 2008; Unsworth and Rondenay 2012). Hence the MT method is useful for investigating subsurface fault distributions, and therefore has the potential to identify tectonic zones by imaging their boundaries.

Here, we present high-resolution MT measurements across Southern Mongolia. Electrical resistivity models of the lithosphere, in combination with previous geological and geophysical data, provide insights into both the shallow surface and deep structure of this region and help to shed light on the distribution of tectonic blocks and the development of the CAOB.

\footnotetext{
(See figure on next page.)

Fig. 1 Map of survey area. a Topographic map of the study area in Southern Mongolia. The profile is marked with a black line (A-A'). Measurement locations are circles; black are magnetotelluric sites and white are telluric-only sites (see text for details); vertical bars indicate measurements from 2016, horizontal bars from 2017, otherwise from 2018. Sites shown in Fig. 6 are marked (2360, 2680, 2690). Blue dashed lines indicate the surface locations of fault zones (black text; Styron 2018; Walker et al. 2007). Names and locations of tectonic zones (grey text) are from Kröner et al. (2010) and Badarch et al. (2002). Local names of mountain ranges are indicated (white text; from Bassa (2012)). Selected villages are indicated for reference (grey squares): Bo Bogd, Ba Bayanlig, Gu Gurvantes. The gold square marks the location of Tsagaan Tsahir Uul (TTU) gold deposit and mining activity. The grey star (labelled BEq) marks the location of the 1957 Bogd rupture, an intraplate earthquake of magnitude 8.4 (Rizza et al. 2015). b Inset map showing location of the survey area in a greater tectonic context. Mongolia is situated between the Siberian craton and the North China and Tarim cratons (dashed grey lines). Southern Mongolia is assembled from accreted terranes amalgamated against the Hangai microcontinent (Badarch et al. 2002). The survey location (grey box), MT profile (red line), Mongolian Altai and Gobi-Altai mountains, political boundary of Mongolia (thin black line), and the capital city, Ulaanbaatar (UB), are indicated
} 


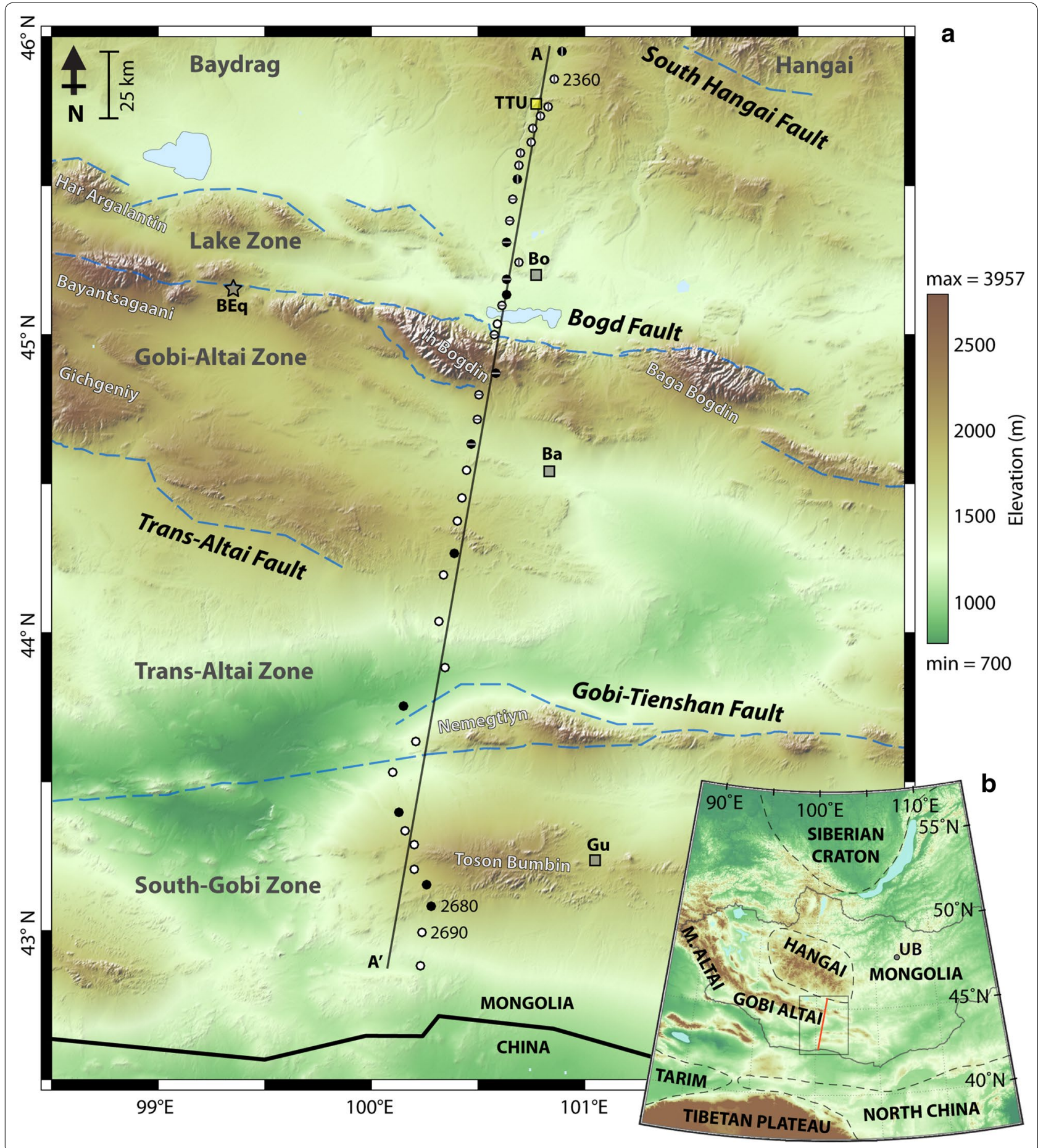

\section{Magnetotelluric data}

\section{Data acquisition and analysis}

Magnetotelluric data consist of electric and magnetic fields measured at the surface of the Earth that are related by a frequency-dependent, complex-valued impedance tensor $(\mathrm{Z})$ that is sensitive to the Earth's subsurface electrical resistivity structure (e.g., Chave and Jones 2012). Apparent resistivity (and impedance phase) are determined over a range of frequencies, with high frequencies sensitive to shallow structure and low frequencies (i.e., long periods) sampling greater depths. 
Beginning in 2016, an array of MT data was collected across Central Mongolia in order to investigate the subsurface electrical resistivity, specifically below the Hangai Dome (Käufl et al. 2020; Comeau et al. 2018a). In 2018, a profile of 20 MT sites was completed in Southern Mongolia, along a longitude of approximately $100.5^{\circ} \mathrm{E}$ and ending near the China-Mongolia border ( $20 \mathrm{~km}$ away). Combining these with previously acquired data, a profile was created (total range: latitude $45.950^{\circ} \mathrm{N}$ to $42.897^{\circ} \mathrm{N}$ ) that will be the focus of this paper (see Fig. 1).

Both MT instruments and telluric-only data-loggers were deployed. Telluric-only data-loggers were developed and built by the University of Münster (Becken et al. 2014), and used non-polarizing $\mathrm{Pb}-\mathrm{PbCl}_{2}$ electrodes, based on the design of Petiau (2000), which are stable for long periods. MT instruments consisted of a combination of Metronix ADU-07e data-loggers (deployed in 2018; provided by the Geothermal Energy and Geofluids group at ETH Zurich, and by the University of Münster) and SPAM Mk IV data-loggers (deployed in 2016 and 2017, see Fig. 1; provided by the Geophysical Instrument Pool Potsdam, with $\mathrm{Ag}-\mathrm{AgCl}$ electrodes). Metronix MFS-06e magnetic induction coils were used to measure the two horizontal magnetic field components. The vertical magnetic field was also measured at most MT sites, but is not used in this study. The electric dipole length was typically chosen to be $60 \mathrm{~m}$. All instruments were powered with batteries and solar panels $(<100 \mathrm{~W})$.

The total period range recorded was $0.00195-5793 \mathrm{~s}$ (half of the sites reached more than 1024 s), providing good resolution within the crust and allowing penetration to upper mantle depths. MT site occupation times were typically less than 3 days. All measurement sites had an average spacing of $8.5 \mathrm{~km}$ (range of 4-15 km), and MT measurements were carried out with an average spacing of $31 \mathrm{~km}$ (range of 5-50 km). This survey design ensured fast and efficient field deployment. Typically, there were two MT sites and a few telluric-only sites recording simultaneously. Inter-site transfer functions were computed between the telluric-only sites and the full MT sites, using a combination of local electric fields and magnetic fields from the base site, as described by Käufl et al. (2020). Some modelling codes are capable of accounting for the independent measurement locations of the electric fields and the magnetic fields (e.g., Key 2016; Grayver 2015; Kalscheuer et al. 2010). This is an improvement over simply using nearby magnetic fields for the telluriconly sites because this approach can introduce some error, specifically near strong resistivity contrasts (e.g., Muñoz and Ritter 2013), especially because the distances between local and base sites in this study are large (cf. Comeau 2015).
The MT data were high quality and had a very low noise level due to the remote measurement location. However, the data suffers from large static shifts (of up to three orders of magnitude), which are constant, frequency-independent offsets of the apparent resistivity caused by near-surface resistivity structure that occurs at a small spatial length scale (e.g., Chave and Jones 2012). To better understand the data and the range of static shifts, the sum of the squared elements of the impedance tensor (ssq-average; Rung-Arunwan et al. 2016) was calculated for each site (Fig. 2). In addition, their geometric mean was calculated, which represents a regional onedimensional (1-D) average and is assumed to balance a random distribution of static shifts. This analysis demonstrated the similarities and differences of the data, in the form of apparent resistivity and phase curves. In addition, it can be used to estimate the average penetration depth of electromagnetic signals by computing the real part of the C-response for each period (Weidelt 1972). It was determined that the measured electromagnetic
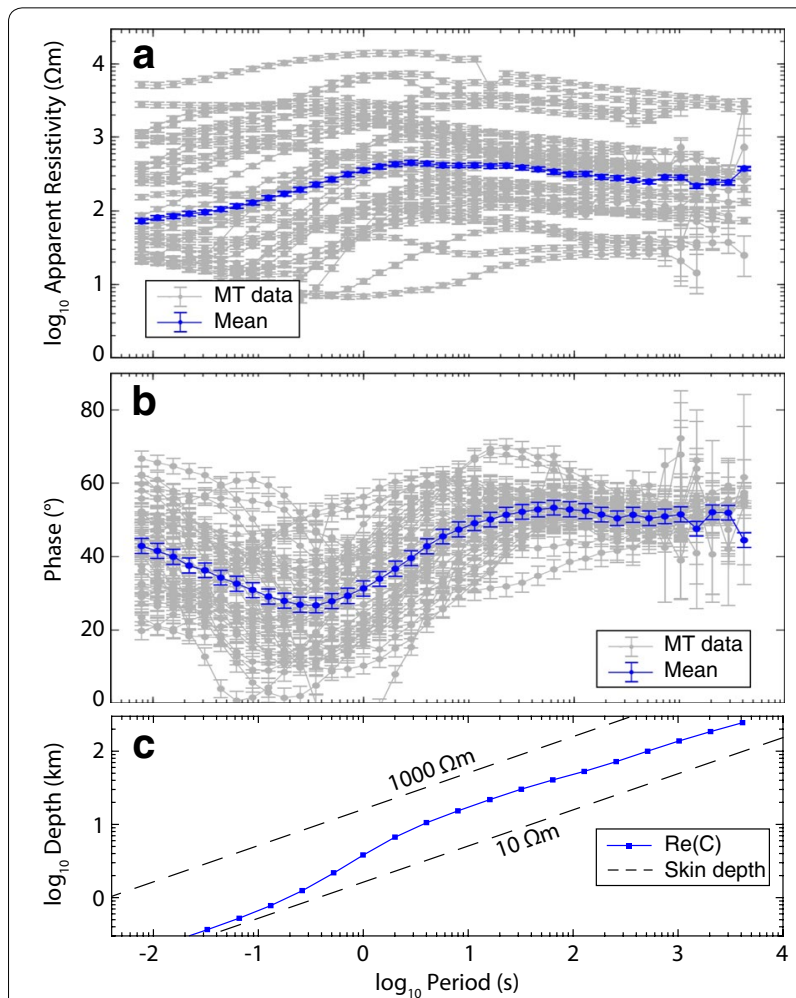

Fig. 2 Data and penetration depth. a Apparent resistivity and $\mathbf{b}$ phase curves from the ssq-average for all individual magnetotelluric sites (grey lines) along the profile and their geometric mean (blue lines). c The penetration depth of electromagnetic signals is calculated, using the real part of the C-response (blue line), based on a conductivity profile obtained from a 1-D inversion of the ssa regional impedance average, and the skin depth (dashed black lines), based on a homogeneous model of $10 \Omega \mathrm{m}$ and $1000 \Omega \mathrm{m}$ 
periods of $1 \mathrm{~s}$ achieve penetration to shallow upper crustal depths of $4 \mathrm{~km}$, periods of $30 \mathrm{~s}$ reach mid- to lowercrustal depths of $30 \mathrm{~km}$, periods of $90 \mathrm{~s}$ reach the bottom of the crust at $45 \mathrm{~km}$ depth (all but four sites reach this period), and periods above $500 \mathrm{~s}$ can penetrate to $100+$ $\mathrm{km}$ depth, which in this region can be within the asthenosphere (Fig. 2c).

Dimensionality analysis of the data determines if the assumption of a two-dimensional (2-D) resistivity model is valid. If it is not, then a full three-dimensional (3-D) analysis may be required to properly model the data. The geo-electric strike direction was estimated for all sites and all periods (Becken and Burkhardt 2004). At short periods $(<1 \mathrm{~s})$, there is no well-defined strike direction because the electromagnetic signals are sampling the near-surface resistivity and are controlled by structures in their immediate vicinity. At longer periods ( $>1 \mathrm{~s}$ ), a welldefined regional strike direction of $\mathrm{N} 104^{\circ} \mathrm{E}$ was observed (Fig. 3; note there exists an inherent $90^{\circ}$ ambiguity). The strike direction is consistent with the trend of the GobiAltai mountain range in this area $\left(\mathrm{N} 95^{\circ} \mathrm{E}-\mathrm{N} 115^{\circ} \mathrm{E}\right)$.

Phase tensor analysis was used to verify this result. The phase tensors (Fig. 3), which are not affected by galvanic distortions such as static shifts, can be plotted in pseudosection view as ellipses and coloured with their phase tensor skew value ( $\psi$; Booker 2014). They will appear as circles for a 1-D subsurface and as ellipses for 2-D or 3-D subsurface conductivity distributions. Skew values for perfect 2-D data are $0^{\circ}$, whereas high skew values $\left(>6^{\circ}\right)$ indicate significant 3-D effects (e.g., Booker 2014). It was found that average skew values across the profile were low (skew $<3^{\circ}, \sim 70 \%$ of data). Hence, the phase tensor analysis confirmed that a 2-D model is valid, although certain regions displayed distortion or local 3-D resistivity structures. To account for this, data with high phase tensor skew values (e.g., $>9^{\circ}$ ) can be omitted. For modelling purposes, the data were mathematically rotated to the geo-electric strike direction $\left(\mathrm{N} 104^{\circ} \mathrm{E}\right)$ and projected along a profile perpendicular to this, following the assumption that the subsurface resistivity does not vary away from the profile (i.e., it is 2-D).

In order to properly account for the effects of galvanic distortion and departures from the 2-D condition, the distortion parameterization of Becken and Burkhardt (2004) was employed. This parameterization yields the distortion angles introduced by Smith (1995) if the 2-D condition is fulfilled. In this case, distortion can be partly removed by constructing an inverse distortion matrix. Otherwise, the telluric vectors exhibit an elliptical polarization state, an admission of departures from true 2-D conditions, or of a non-optimal principal axis (corresponding to the chosen geo-electric strike direction). However, all data have errors and any 2-D condition can only be confirmed to within the errors of the ellipticities. Non-vanishing ellipticities can be back-propagated into impedance errors, as in Becken et al. (2011). Thus these new impedance errors make departures from the 2-D condition indistinguishable, within the errors. This procedure of adjusting the errors corresponds to the downweighting of 3-D effects (i.e., using the errors in the inversion as weightings).

\section{2-Dimensional data modelling}

A 2-D electrical resistivity model (Fig. 4) was created from the MT data using the inversion algorithm MARE2DEM (Modeling with Adaptively Refined Elements for 2-Dimensional Electromagnetics; Key 2016). This algorithm uses a dual-grid approach by computing the forward solution with an adaptive finite-element method that automatically generates and refines unstructured triangular elements. Furthermore, it is capable of properly handling inter-site transfer functions computed for the telluric-only sites.

The profile contained $39 \mathrm{MT}$ sites and included data at 39 periods, in the range of 0.00781-4096 s. Both modes of the impedance tensor were inverted (i.e., the transverse magnetic or TM mode with electric currents flowing along the profile and the perpendicular transverse electric or TE mode). Käufl et al. (2018) investigated the effect of topography when modelling MT data, and showed that the distortion of MT data can occur when it is not accounted for. Topography was included in the model, because the elevation in this region varies from 700 to $3957 \mathrm{~m}$ above sea level (crossing Ih Bogdin in the Gobi-Altai mountains). The starting model consisted of homogenous $300 \Omega \mathrm{m}$ halfspace, which corresponds to the mean value for the entire region, as determined by the previous analysis (see Fig. 2).

In order to keep the model resolution high and to fit a broad period range, the modelling mesh used seven layers, with the dimensions of the mesh elements increasing downwards (see Fig. 4). Between the surface and sea level, a fine mesh of triangular elements had dimensions of approximately $0.5 \mathrm{~km}$. Below this, from sea-level to $2 \mathrm{~km}$ depth below sea-level, the elements had dimensions of $1 \mathrm{~km}$; from 2 to $10 \mathrm{~km}$ depth, dimensions of $2 \mathrm{~km}$; from 10 to $45 \mathrm{~km}$ depth (the bottom of the crust), dimensions of $3 \mathrm{~km}$; from 45 to $90 \mathrm{~km}$ depth, dimensions of $5 \mathrm{~km}$; from 90 to $200 \mathrm{~km}$ depth, dimensions of $10 \mathrm{~km}$; and finally from 200 to $1000 \mathrm{~km}$ depth the elements expanded smoothly to a maximum dimension of $150 \mathrm{~km}$. In total, the modelling mesh had 31,701 triangular elements.

Because real measurement errors are small, all data were assigned an error floor, that is a minimum error value. To ensure a close fit to the data, both TE and TM mode phase components were assigned an error floor of 

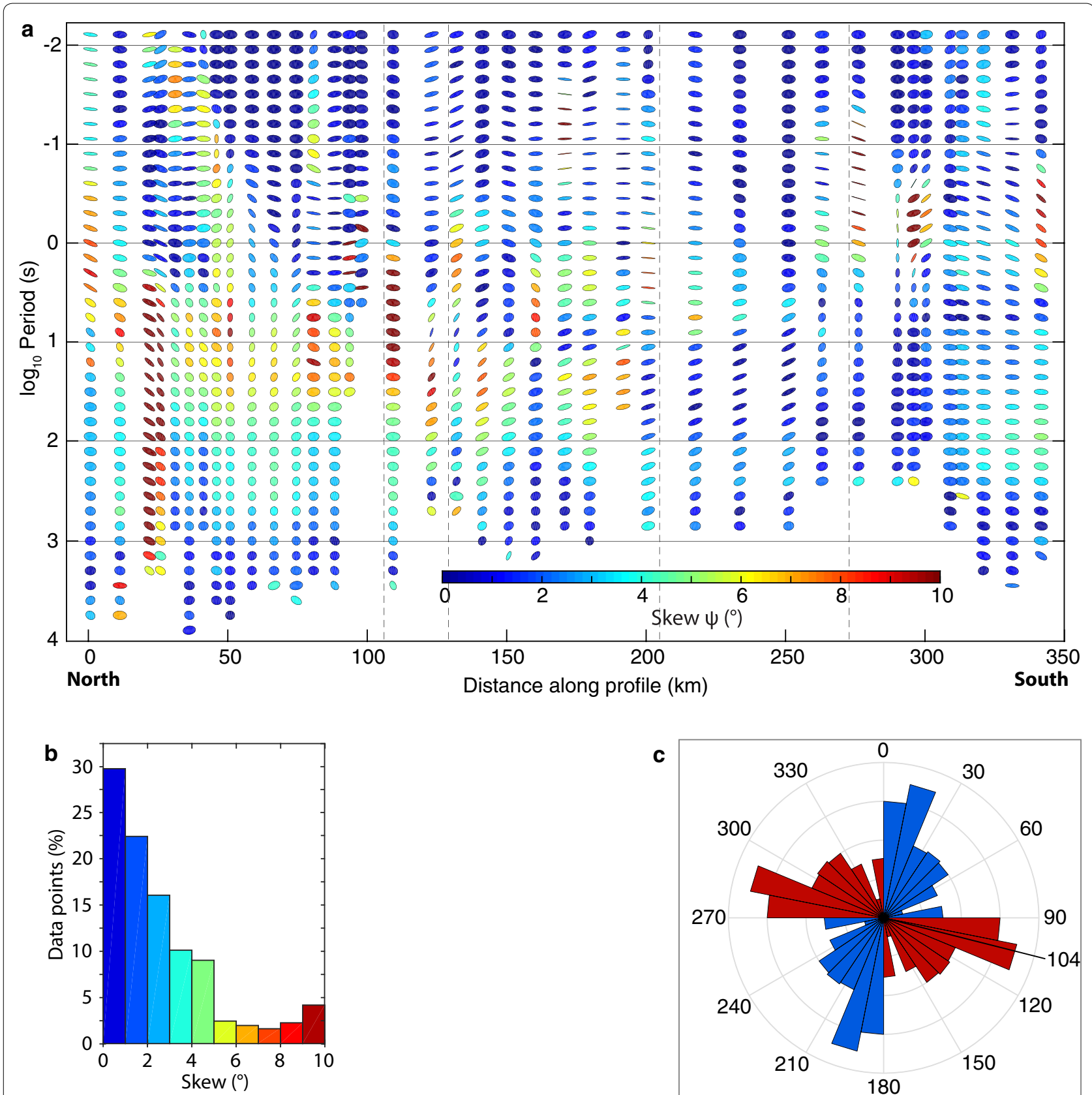

Fig. 3 Phase tensor and geo-electric strike analysis. a Phase tensor ellipses for all periods and all sites plotted along the profile and coloured with their skew values. The phase tensors indicate 1-D geo-electric structure when circular in shape and 2-D or 3-D structure when elliptical. Low skew values $\left(\psi<3^{\circ}\right.$; blue colour) indicate relatively 1-D or 2-D data. High skew values $\left(\psi>6^{\circ}\right.$; yellow to red colours) indicate significant distortion or 3-D effects. Dashed grey lines indicate separate tectonic zones. $\mathbf{b}$ A histogram of skew values illustrates that the majority of data points have skew $<2^{\circ}$ and most are $<5^{\circ}$. c Rose diagram (circular histogram) of the geo-electric strike direction along the profile for 1-4096 s. The preferred direction is estimated to be $\mathrm{N} 104^{\circ}$ E. Note a $90^{\circ}$ ambiguity exists (blue and red colours)

$1.43^{\circ}$ (corresponding to a $2.5 \%$ relative error on impedance, i.e., $\Delta|\mathrm{Z}| /|\mathrm{Z}|$, or a $5 \%$ error on apparent resistivity). Similarly, the TM mode apparent resistivity was assigned an error floor of $10 \%$. Initially, the TE mode apparent resistivity was assigned a high error floor of $100 \%$ to reduce the notable influence of the observed static shift effect (e.g., Chave and Jones 2012; Comeau et al. 2018a). This allows the inversion algorithm to fit the TE mode apparent resistivity curve shape, due to the closely fitted phase component, but accounts for any static shift by 


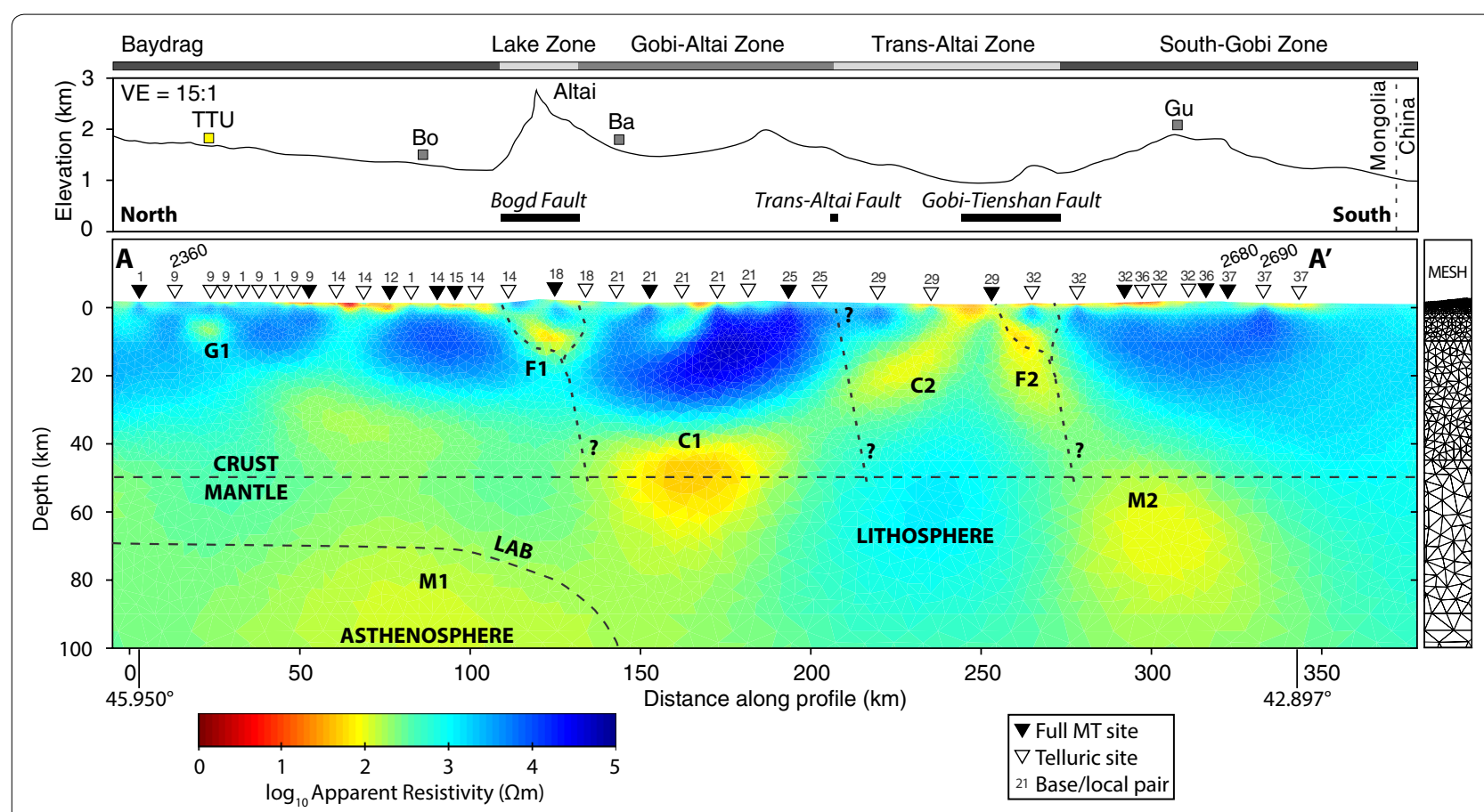

Fig. 4 Resistivity model. The preferred 2-D resistivity model obtained with the MARE2DEM inversion algorithm (Key 2016) for magnetotelluric (MT) data at 39 sites along profile A-A' (see map in Fig. 1). A combination of full MT sites (black triangles) and telluric-only sites (white triangles) was used. The base site used for inter-site transfer functions (with a local site) is indicated by the number above each site. Sites shown in Fig. 6 are marked. Distances are along the profile (approximately from north to south along longitude $100.5^{\circ} \mathrm{E}$ ); latitudes of end sites are marked. The side panel shows a part of the modelling mesh used. Topography was included in the model and is shown in the upper panel with a vertical exaggeration (VE) of 15:1. The locations of nearby villages are displayed for reference (grey squares), as in Fig. 1: Bo Bogd soum, Ba Bayanlig soum, Gu Gurvantes soum. Gold square marks the location of Tsagaan Tsahir Uul (TTU) gold deposit. Names and locations of tectonic zones (grey bars at top) are from Kröner et al. (2010). The surface locations of prominent fault zones are indicated (black bars; Styron 2018; Walker et al. 2007). Fault extension in the subsurface (dashed grey lines) is speculated. Anomalous features in the upper crust appear coincident with known surface fault positions. They are believed to represent the boundaries of accreted terranes and their positions define distinct tectonic zones. Lower-crustal conductors may be in agreement with an allochthonous and relaminated lower crust. The seismically inferred crust-mantle boundary is at approximately $45 \mathrm{~km}$ (Petit et al. 2008). The proposed lithosphere-asthenosphere boundary (LAB) is indicated; it deepens towards the south

allowing the curve to be shifted for all frequencies, within error. The inversion algorithm smoothly converged after 11 iterations with the total root-mean-square (RMS) misfit reduced from 10.8 to 1.71 , indicating that the model fits the measured data. The inversion was then re-started with the target misfit adjusted so that the inversion enters phase two of the Occam algorithm, where it seeks the model with the smallest roughness norm. After three iterations it produced a smooth model, which is the preferred model. As an additional step, the static shift solver was implemented, which uses the average of the model fit residuals to estimate a frequency-independent shift for each site, and hence the TE mode apparent resistivity was assigned an error floor of $10 \%$ (equal to that of the TM mode; the error floor of other components did not change). In this case, the total RMS misfit was reduced from 2.33 to 1.98. Careful comparisons of the measured data and the modelled data indicate that the model fits the measured data (Figs. 5, 6). Furthermore, the fit is equally distributed between both modes and relatively evenly spread across all sites, indicating that the model is not unfairly influenced by any subset of the data.

Many combinations of inversion model parameters and inversion approaches were thoroughly investigated in order to test the robustness of model features. Overall, it was found that the main resistivity features of the model did not heavily depend on any specific scheme and the preferred model shown here is representative of most cases. For example, no significant changes in the main model features were observed when the geo-electric strike angle was varied slightly (i.e., $\pm 10^{\circ}$ ), or when the starting model was reasonably varied (e.g., to a layered starting model, or to a $100 \Omega \mathrm{m}$ halfspace). Only relatively minor changes in the data fit or time of convergence were seen. Additionally, the inversion was carried out using only data with low phase tensor skew $\left(\psi<6^{\circ}\right)$ to better match the assumptions of 2-D modelling and eliminate any off-profile effects due to 3-D structure. Similarly, we 


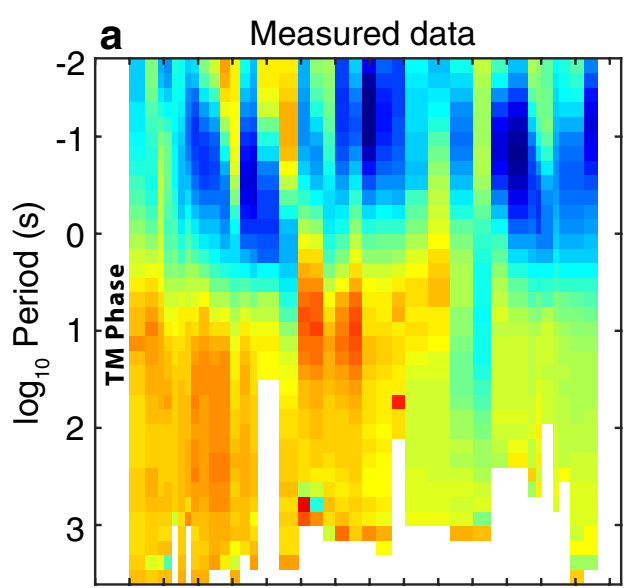

b Modeled data
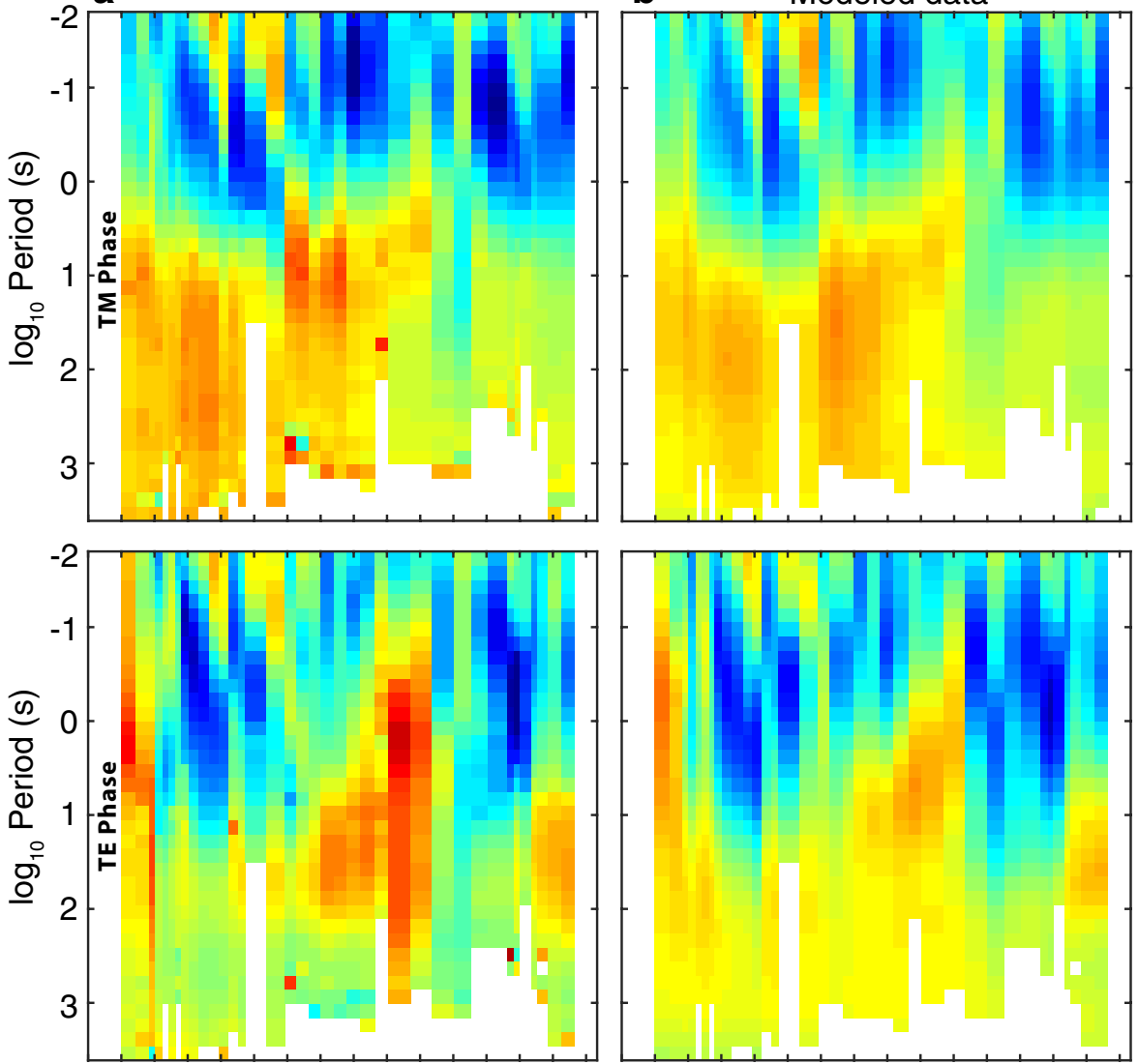

80
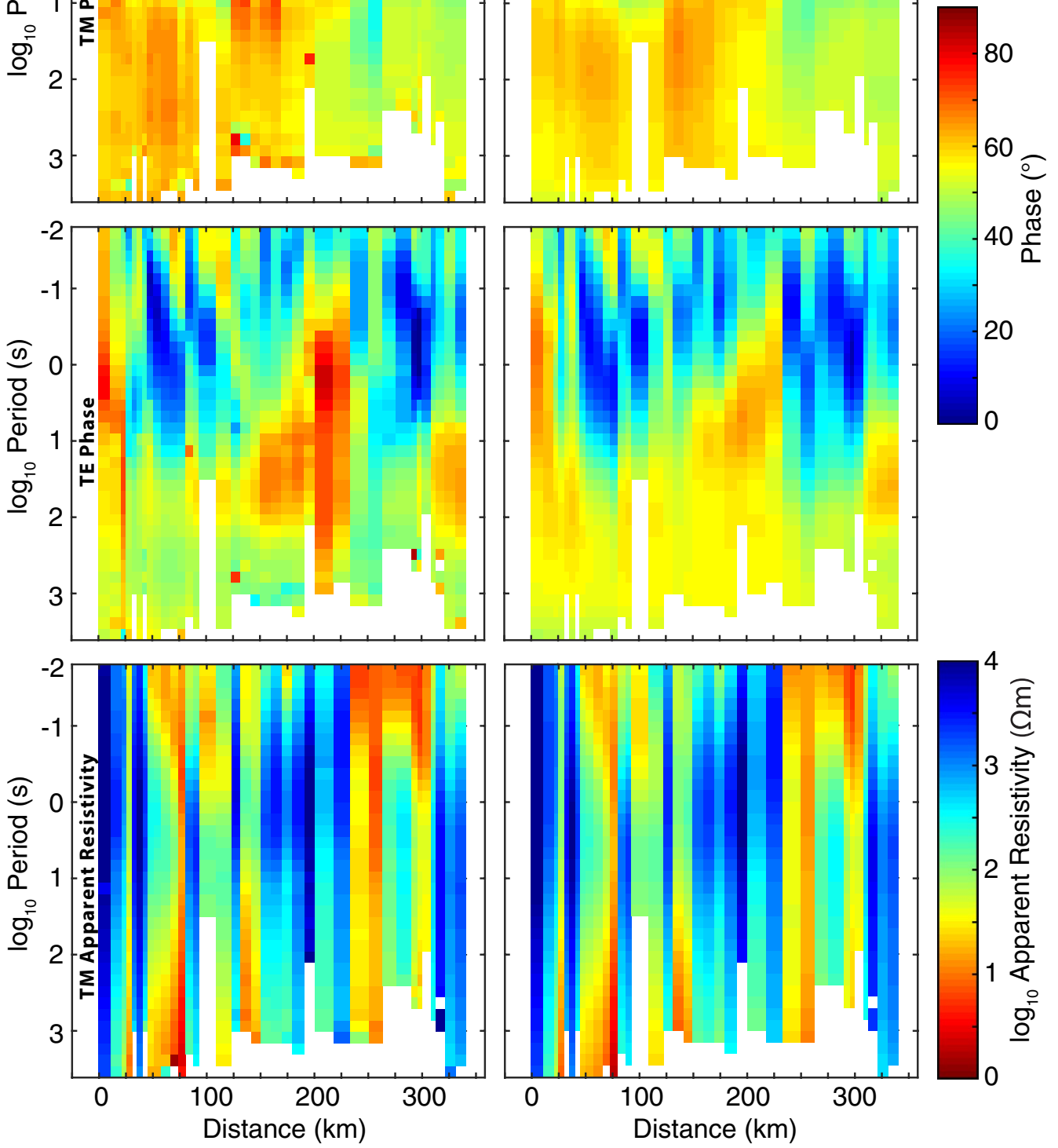

Fig. 5 Data fit shown with pseudosections. a Pseudosections of the measured magnetotelluric data and $\mathbf{b}$ the modelled data, for TM mode impedance phase, TE mode impedance phase, and TM mode apparent resistivity, respectively. Pseudosections of the TE mode apparent resistivity are not shown because data fit evaluation is complicated by static shifts

removed short period data $(<1 \mathrm{~s})$, representative of the near-surface structure $(<5 \mathrm{~km})$ which were generally more difficult to fit. In both cases the data fit improved, but the main model features did not undergo any relatively significant changes, despite a reduction in model resolution. Furthermore, model resolution and sensitivity were investigated systematically using synthetic inversions. This included removing model features (i.e., replacing a conductor with its adjacent resistivity values) and observing the change in data fit and re-inverting to 

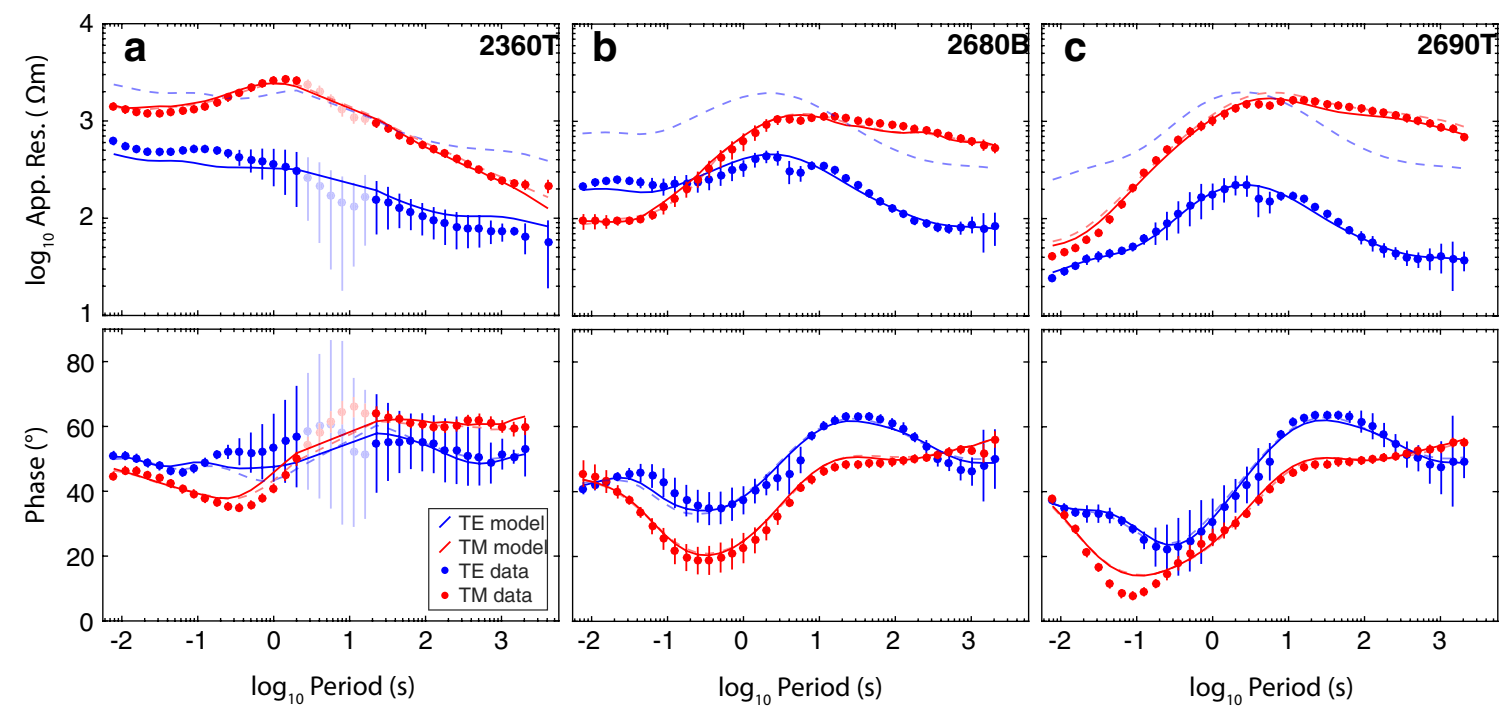

Fig. 6 Data fit shown with apparent resistivity and phase curves. Characteristic data fit for the resistivity model. Data are points, both apparent resistivity (upper panels) and phase (lower panels), with corresponding error bars, and model responses are lines, dashed for the initial inversion run and solid for the additional run, where static shifts have been corrected. a A MT site with data points that had high phase tensor skews and were removed (shaded points near a period of $10 \mathrm{~s}$ ). Note that, rather than removing data, the adjusted error bars effectively down-weight the non 2-D segments of the data (see text for details). b A MT site and $\mathbf{c}$ is an adjacent telluric-only site, a base and local pair

investigate if features were re-introduced. These tests demonstrated that the main features are robust and required. Crustal features of the model are particularly well-constrained. However, the geometry of the upper mantle features is not well-constrained, and can vary. None of the variations observed affect the overall interpretation of the preferred model.

\section{Results and discussion Modelling results}

The 2-D resistivity model derived from the MT data reveals several interesting features, described and discussed below. Variations in resistivity can be due to multiple causes (including different rock types, the presence of fluids, or partial melts), and therefore any interpretation of model features benefits from additional information (e.g., Unsworth and Rondenay 2012).

The near-surface layer $(<1.5 \mathrm{~km})$ has a highly variable resistivity (3-3000 $\Omega \mathrm{m}$; see Fig. 4). It features two highly conductive regions $(<30 \Omega \mathrm{m})$, in the Valley of Lakes (near Bogd), which is an internally drained basin between the Hangai and Gobi-Altai mountains (e.g., Cunningham 2001), and north of the Nemegtiyn mountain range (near Gurvantes), which is a Cenozoic alluvial basin (Badarch et al. 2002) (see Fig. 1 for locations). These conductive features may be caused by porous sediments in these regions or by increased salinity due to evaporite minerals. Another shallow $(<5 \mathrm{~km})$ conductive feature $(\sim 100 \Omega \mathrm{m}$; G1) is seen at the northern end of the profile. It is located below the Tsagaan Tsahir Uul gold deposit, which is an area of significant mineralization, containing important sources of gold and copper (e.g., Buchan et al. 2001; Dejidmaa and Badarch 1999). The observed electrical signature may be associated with emplaced mineralization in the upper crust, or past hydrothermal fluid alteration (see Comeau et al. 2018b).

The upper crust $(<20 \mathrm{~km})$ is generally resistive $(1000-$ $30,000 \Omega \mathrm{m}$ ). This can be explained by the Neoproterozoic basement rocks and Paleozoic ultra-mafic rocks believed to comprise this region (e.g., Guy et al. 2015; Badarch et al. 2002). Within the upper crust, MT data detect two prominent anomalously conductive features (30-100 $\Omega \mathrm{m}$; F1 and F2), imaged as elongated structures stretching nearly vertically through the upper crust to depths of $20+\mathrm{km}$ and dipping slightly southwards. The feature F1 was previously imaged by Comeau et al. (2018a) and has a consistent geometry and resistivity, despite differences in data preparation and inversion methodology. Both features F1 and F2 are well resolved by the dense MT site spacing. Faults and suture zones are regions of fractured and weakened crust that may contain circulating fluids or hydrothermally altered zones that significantly lower the electrical resistivity (e.g., Unsworth and Rondenay 2012). Therefore, these features are interpreted to represent suture zones.

In fact, these anomalous features are spatially associated with the surface expressions of known fault zones and inferred terrane boundaries (Badarch et al. 
2002), which are expected to be deep-reaching, possibly lithospheric-scale (Calais et al. 2003). The feature F1 is coincident with the location of the large, seismically active, left-lateral strike-slip and transpressional Bogd fault zone at the base of Ih Bogdin and the GobiAltai mountain range (Walker et al. 2007; Calais et al. 2003). Moreover, it is known to be a major lithological boundary (Badarch et al. 2002), and is thought to be an ancient suture zone (e.g., Xiao et al. 2015). The epicentre of a large rupture event in 1957, which had a strike-slip mechanism and a moment magnitude larger than 8 , is located less than $100 \mathrm{~km}$ to the west, near the Bayantsagaani mountain range (e.g., Calais et al. 2003, and references therein; Rizza et al. 2015). Furthermore, the locations of recently measured earthquakes (see Meltzer et al. 2019) align on each side of the feature F1, at depths of $0-17 \mathrm{~km}$. The feature F2 is coincident with the major Gobi-Tienshan fault as it passes near the Nemegtiyn mountain range, which is a left-lateral strike-slip fault that stretches westward into China and can be continuously traced for more than $1000 \mathrm{~km}$ (e.g., Styron 2018; Walker et al. 2007).

Both features appear to dip southwards, approximately $70-80^{\circ}$ to the horizontal. This is consistent with geological estimates of fault dips in this region (e.g., Rizza et al. 2015). Furthermore, these fault zones each consist of two surface traces with a broad zone between. Because a combination of strike-slip and transpressional faulting (along restraining bends) is observed here, we speculate that this may indicate a subsurface flower-structure, with the fault segments joining into a single strand in the basement. The fault extent at greater depths is speculative, but because these faults represent terrane sutures they are believed to be lithospheric-scale (e.g., Calais et al. 2003), that is, they are expected to pass through the crust into the upper mantle.

There is no near-surface conductive feature spatially aligned with the small Trans-Altai fault, located at the southern edge of the Gobi-Altai plateau and the Gichgeniy mountain range (e.g., Walker et al. 2007; Guy et al. 2014). However, a strong electrical signature is likely absent because deformation along this fault is primarily located to the west, where there is a step in surface topography, as indicated by the end of the mapped surface trace $\sim 20 \mathrm{~km}$ west of the profile (see Fig. 1; Walker et al. 2007). Although tectonostratigraphic maps show this boundary extends farther east (Kröner et al. 2010). Additionally, this fault has very little seismic activity, historic or current (e.g., Meltzer et al. 2019). However, a deeper (mid-crustal) conductive anomaly (50-100 $\Omega \mathrm{m}$; C2) may be related to this fault system (see below). Similarly, no conductive feature is seen further south near the Toson Bumbin mountain range.
In contrast to the upper crust, the lower crust $(20-45 \mathrm{~km})$ has a generally moderate resistivity (300$1000 \Omega \mathrm{m})$. Two lower-resistivity zones $(50-100 \Omega \mathrm{m})$ are observed beneath the Gobi-Altai zone $(\mathrm{C} 1 ; 30-50 \mathrm{~km}$ depth, it appears smeared downwards) and the Trans-Altai zone $(\mathrm{C} 2 ; 15-30 \mathrm{~km}$ depth). The low-resistivity zones are disconnected and offset, signifying a crustal boundary. According to global models for Curie-point depths (Li et al. 2017), the $550{ }^{\circ} \mathrm{C}$ temperature isotherm is at a depth of approximately $20 \mathrm{~km}$ in this region, indicating that feature $\mathrm{C} 1$ is located below the brittle-ductile transition and feature $\mathrm{C} 2$ is near it. The low-resistivity zones suggest that the crustal (lithotectonic) blocks are not homogenous. This may therefore agree with previous studies which have argued that an enigmatic and allochthonous lower crust exists below the Gobi-Altai zone and Trans-Altai zone (Guy et al. 2015; Kröner et al. 2010). One study, based on geochemical constraints and gravity modelling, concluded that the lower crust of the Mongolian CAOB in this region is felsic and juvenile metamorphosed continental crust due to the relamination of the Khantaishir magmatic arc (Guy et al. 2015). Therefore, these low-resistivity zones may be controlled by past deformation episodes. Alternatively, the anomaly $\mathrm{C} 2$ may be related to an ancient accretionary wedge associated with the Trans-Altai fault (Badarch et al. 2002; Guy et al. 2015) due to a previous subduction event north of the South-Gobi zone (e.g., Xiao et al. 2015). In contrast, the South-Gobi zone appears to have a homogenous lower crust $(>1000 \Omega \mathrm{m})$, which is consistent with the fact that it is believed to consist of a Precambrian cratonic basement (Guy et al. 2014).

Although resolution at greater depths is limited, the resistivity model images several interesting features within the upper mantle. Below the northern portion of the profile, a conductive feature ( $100 \Omega \mathrm{m}$; M1) appears below a depth of $70 \mathrm{~km}$. This is believed to be a continuation of the shallow asthenosphere previously detected below Central Mongolia ( $70 \mathrm{~km}$; Comeau et al. 2018a), which agreed with the architecture of the lithosphere-asthenosphere boundary predicted from a seismic profile across central Mongolia (Petit et al. 2008). For the southern portion of the profile (south of the Gobi-Altai Mountains), the MT data indicate a resistive upper mantle $(\sim 1000 \Omega \mathrm{m})$. This gives evidence for a thick lithosphere $(>100 \mathrm{~km})$ below Southern Mongolia. Hence, this indicates the presence of a steep lithospheric step. This is corroborated by modern global tomography models (Ho et al. 2016) that predict an increase of $\sim 36 \mathrm{~km}$ in the thickness of the (thermal) lithosphere across the entire profile (from latitude $45^{\circ} \mathrm{N}$ to $43^{\circ} \mathrm{N}$ ). In this study, the location of the lithospheric step is clearly imaged beneath the Gobi-Altai mountains, which can possibly be explained by the major suture zone running along the Main Mongolian Lineament (e.g., Xiao 
et al. 2015). Other studies (Comeau et al. 2018a; Petit et al. 2008) placed the step farther north, and related it to the major suture zone formed by the closure of the MongolOkhotsk ocean (e.g., Van der Voo et al. 2015; Sheldrick et al. 2018). In addition, an anomalous feature is imaged in the upper mantle below the South-Gobi zone (M2; 200$300 \Omega \mathrm{m}$ ). It is unexplained, but may be related to the lithospheric-scale suture of the South-Gobi zone along the Gobi-Tienshan fault. Alternatively, it could be related to hydrated lithosphere, thought to exist in this region from previous subduction events, or it could be a consequence of a very local shallowing asthenosphere (e.g., Sheldrick et al. 2018).

\section{Constraints on tectonic boundaries}

Combining geological, geochemical, and geochronological data, Badarch et al. (2002) composed a model of Mongolia consisting of 44 separate lithostratigraphic domains interpreted as terranes. In Southern Mongolia, to firstorder, narrow, east-west oriented terranes were amalgamated and accreted about a central nucleus (Badarch et al. 2002), which was separated by a major suture known as the Main Mongolian Lineament (e.g., Kröner et al. 2010; Xiao et al. 2015). This nucleus consisted of the cratonic block of Central Mongolia (Hangai) and microcontinent fragments, including the Baydrag block. Although terrane accretion was spatially and temporally complex, it is believed to have generally occurred north to south with time (e.g., Badarch et al. 2002). Terranes are expected to be fault-bounded fragments, but the lithostratigraphic domains do not consistently align with the position of known surface faults. Kröner et al. (2010), revisiting older models, simplified Southern Mongolia into four principal tectonic zones, or lithotectonic blocks (see Fig. 1). Geophysical potential field data analysed by Guy et al. (2014; gravity and magnetics) revealed minor disagreements in the positions of several suspected terranes, but supported the principal tectonic zones.

The Baydrag block is an early Proterozoic continental fragment overlain by a Cambrian passive margin (Guy et al. 2014; Kröner et al. 2010; Badarch et al. 2002). It is located in the Valley of Lakes, south of the Hangai, and separated by the South Hangai fault zone, and north of the Gobi-Altai (e.g., Badarch et al. 2002). the lake zone is a narrow tectonic zone adjacent to the Bogd fault system, and the Main Mongolian Lineament, that reaches from Baga Bogdin and Ih Bogdin mountain ranges to the Har Argalantin and Bayantsagaani mountain ranges and farther west (Kröner et al. 2010). Guy et al. (2015) describe it as an Early Cambrian accretionary wedge composed of volcanic arcs (possibly island arcs) and accretionary prisms thrust over the basement rocks of the Baydrag block. South of the Gobi-Altai mountains is a plateau, which defines the Gobi-Altai zone, which ends at the Trans-Altai fault. The Gobi-Altai zone consists of thick Cambrian/Ordovician volcano-sedimentary sequences interpreted as an accretionary wedge covered by Silurian/Devonian passive margin and high-grade metamorphic rocks (e.g., Guy et al. 2015). The Trans-Altai zone lies to the south and ends at the Gobi-Tienshan fault. This zone consists of Devonian marine sediments and volcanic rocks, representing a passive margin and a volcanic arc, as well as deeper ultra-mafic rocks that give evidence for the formation of oceanic crust during the Early Devonian, which corresponds with an ocean opening (e.g., Guy et al. 2015). South of this is the South-Gobi zone, which continues to the Mongolia-China border and beyond to another major suture zone in Northern China (Kröner et al. 2010; Xiao et al. 2015). This zone consists of Ordovician/Silurian siliciclastic sediments, typical of continental-margins, and Carboniferous volcanic rocks atop a Precambrian cratonic basement (Guy et al. 2014). In addition, both the Trans-Altai zone and the South-Gobi zone have intrusive Carboniferous and Permian granitoids, found to be related to basement melting from zircon analysis and located along the main tectonic boundaries, coinciding with weakened deformation zones (Guy et al. 2015).

Tectonic zones and terranes, in the classic sense, are fragments and must be bounded by suture zones, which are often deep-reaching. Therefore, by identifying suture zones, the terrane boundaries, we can identify individual terranes. However, ancient suture zones, especially those that have undergone convergent deformation, as is the case in Southern Mongolia, may be obscured and difficult to detect on the surface (e.g., Dewey 1977). Fortunately, faults and suture zones generally contain fluids, giving them an anomalous electrical signature compared to their surroundings, and allowing us to image them (Türkoğlu et al. 2008; Unsworth and Rondenay 2012).

As discussed above, the resistivity model clearly images several major fault zones. Therefore, the model agrees with the simplification of Kröner et al. (2010) for four principal tectonic zones (see Fig. 4). Nevertheless, distinct lithologies may exist within each tectonic zone, although their resistivity differences, due to differences in petrophysical properties and rock types, are not readily distinguishable, but we can conclude that they are not fault bounded. The distinct lithostratigraphic domains of Badarch et al. (2002) can be adjusted slightly so that they fit within the tectonic zones or along the suture zones. It should be noted that, from the resistivity model, we separate the tectonic regions based on the bounding faults only, rather than on other geological, geochronological, or structural constraints, which may cause small discrepancies with the inferred boundaries drawn by others. 


\section{Conclusions}

In this study, MT and telluric-only data were collected along a $\sim 350-\mathrm{km}$-long profile crossing Southern Mongolia, part of the CAOB, from the Hangai Mountains, across the Gobi-Altai Mountains, to the China-Mongolia border. The data were used to generate a high-resolution, 2-D electrical resistivity model of the crust and upper mantle, presented here. The electrical resistivity model offers new insights into the structure of Southern Mongolia, which plays an important role in understanding the origin and evolution of the $\mathrm{CAOB}$.

Various attempts have been made to divide Southern Mongolia into distinct lithostratigraphic or tectonic regions, typically attributed to accreted terranes. However, there has been some controversy about the exact locations and boundaries of these regions. Terranes are believed to be separated by faults or suture zones, which are expected to be deep-reaching, but which may be difficult to observe at the surface. The resistivity model shows a clear transition in crustal properties across this region. Generally resistive upper crustal blocks are separated by well-resolved, anomalously conductive features that reach through the upper crust. They are spatially coincident with major surface fault zones, specifically the Bogd fault system, the Gobi-Tienshan fault system, and, to a lesser degree, the Trans-Altai fault system. Moreover, these features, which are well resolved by the dense MT site spacing, appear to be dipping slightly southwards, in agreement with geological estimates of fault dip. These features are interpreted as suture zones and tectonic boundaries between terranes or lithotectonic blocks. Therefore, the MT data support evidence for the division of Southern Mongolia into four principal tectonic zones, in agreement with other authors (e.g., Kröner et al. 2010; Guy et al. 2015), despite evidence for highly variable surface geology and multiple distinct lithostratigraphic domains (e.g., Badarch et al. 2002). We propose that fault zones congruent with the edges of these tectonic zones are natural boundaries, which is largely in agreement with tectonic zone boundaries previously determined by potential field methods (Guy et al. 2014).

The lower crust $(20-45 \mathrm{~km})$ is distinct, having a lower resistivity overall and several low-resistivity zones ( $100 \Omega \mathrm{m}$ ) below the Gobi-Altai and Trans-Altai zones. This is in agreement with studies that have argued for an allochthonous lower crust in this region, emplaced tectonically into its present position, that has been relaminated and metamorphosed (Guy et al. 2015; Kröner et al. 2010). We propose that future seismic data should be acquired here to provide alternative evidence of lithospheric structure.
The MT data indicate a thick lithosphere below Southern Mongolia (>100 km), although penetration and resolution is limited at these depths. This is in contrast to the thin lithosphere $(\sim 70 \mathrm{~km})$ previously reported below Central Mongolia (e.g., Petit et al. 2008; Comeau et al. 2018a), attributed to a local asthenospheric upwelling. Therefore, a steep lithospheric step is believed to exist, likely below the Gobi-Altai Mountains, highlighting the importance of this region as a major lithospheric boundary within the CAOB.

\section{Abbreviations \\ CAOB: Central Asian Orogenic Belt; MT: magnetotelluric; 1-D: one-dimensional; 2-D: two-dimensional; 3-D: three-dimensional; TM: transverse magnetic; TE: transverse electric; RMS: root mean square.}

\section{Acknowledgements}

This research was financially supported by the DFG (Grant \# BE 5149/6-1) and the SNF (Grant \# 200021L_162660/1). MB is funded through a DFG Heisenberg Grant (5149/7-1, 5149/9-1). We thank Kerry Key for providing the 2-D MT inversion code. We thank the Geothermal Energy and Geofluids group at ETH Zurich for the use of their MT instruments in 2018 and the Geophysical Instrument Pool Potsdam for the use of their MT instruments in 2016 and 2017. We thank all those who helped collect the data and provided field support, especially our colleagues from the Institute of Astronomy and Geophysics at the Mongolian Academy of Sciences.

\section{Authors' contributions}

All authors were involved with the work. MJC helped collect the data, performed data processing, analysis, and modelling, interpreted the data, and prepared the manuscript. MB helped collect the data and assisted with the modelling and interpretation. JSK helped collect the data and performed data processing and analysis. AVG and AVK helped collect the data and assisted data analysis. ST and EB helped collect the data and supported field logistics. SD helped organize and manage field measurements. All authors read and approved the final manuscript.

\section{Funding}

This research was financially supported by the DFG (Grant \# BE 5149/6-1) and the SNF (Grant \# 200021L_162660/1). The funding bodies had no further role in the study design, data collection, data analysis, data interpretation, nor in the manuscript writing.

\section{Availability of data and materials}

The MT data collected for this study are archived and can be accessed by contacting the German Research Centre for Geosciences.

Ethics approval and consent to participate

Not applicable.

\section{Consent for publication}

Not applicable.

\section{Competing interests}

The authors declare that they have no competing interests.

\section{Author details}

${ }^{1}$ Institut für Geophysik, Universität Münster, Corrensstrasse 24, 48149 Münster, Germany. ${ }^{2}$ Institute of Geophysics, Swiss Federal Institute of Technology (ETH), Sonneggstrasse 5, 8092 Zurich, Switzerland. ${ }^{3}$ Institute of Astronomy and Geophysics, Mongolian Academy of Sciences, P.O.B-152, Ulaanbaatar 13343,

Mongolia.

Received: 28 June 2019 Accepted: 7 January 2020

Published online: 16 January 2020 


\section{References}

Badarch G, Cunningham WD, Windley BF (2002) A new subdivision for Mongolia: implications for the Phanerozoic crustal growth of Central Asia. J Asian Earth Sci 21:87-110

Bassa G (2012) Mongolia geographical map 1:2,000,000. GiziMaps, Budapest. ISBN 978-9-63-868082-2

Becken M, Burkhardt H (2004) An ellipticity criterion in magnetotelluric tensor analysis. Geophys J Int 159:69-82

Becken M, Ritter O, Bedrosian PA, Weckmann U (2011) Correlation between deep fluids, tremor and creep along the central San Andreas fault. Nature 480(7375):87-90

Becken M, Schmalzl J, Bömer B, Ueding S (2014) Development of a E-field data logger and of time series processing tools in matlab. In: Proceedings of the 22nd EM induction workshop, Weimar, Germany, 24-30 August 2014

Booker J (2014) The magnetotelluric phase tensor: a critical review. Surv Geophys $35: 7-40$

Buchan C, Cunningham D, Windley BF, Tomurhuu D (2001) Structural and lithological characteristics of the Bayankhongor Ophiolite Zone, Central Mongolia. J Geol Soc 158:445-460

Calais E, Vernolle M, San'kov V, Lukhnev A, Miroshnitchenko A, Amarjargal S, Déverchère J (2003) GPS measurements of crustal deformation in the BaikalMongolia area (1994-2002): implications for current kinematics of Asia. J Geophys Res 108:1-14

Chave AD, Jones AG (eds) (2012) The magnetotelluric method: theory and practice. Cambridge University Press, Cambridge

Comeau MJ (2015) Electrical resistivity structure of the Altiplano-Puna magma body and volcan uturuncu from magnetotelluric data. Dissertation, University of Alberta, Edmonton, Canada, p 337. https://doi.org/10.7939/R3C24 QW2S

Comeau MJ, Käufl JS, Becken M, Kuvshinov AV, Grayver AV, Kamm J, Demberel S, Sukhbaatar U, Batmagnai E (2018a) Evidence for fluid and melt generation in response to an asthenospheric upwelling beneath the Hangai Dome, Mongolia. Earth Planet Sci Lett 487:201-209

Comeau MJ, Käufl JS, Becken M, Kuvshinov AV, Grayver AV, Kamm J, Demberel S, Batmagnai E, Tserendug S, Eldev-Ochir B, Nasan-OchirT (2018b) Electrical resistivity models reveal mineralization and fault systems in the Valley of the Lakes, south-central Mongolia. In: Proceedings of the 24th EM induction workshop, Helsingør, Denmark, August 13-20, 2018

Cunningham WD (2001) Cenozoic normal faulting and regional doming in the southern Hangay region, Central Mongolia: implications for the origin of the Baikal rift province. Tectonophysics 331:389-411

Dejidmaa G, Badarch G (1999) Summary of pre-accretionary and accretionary metallogenic belts of Mongolia. In: Nokleberg WJ, Naumova W, Kuzmin MI, Bounaeva TV (eds) Preliminary publications book 1 from project on mineral resources, metallogenesis, and tectonics of Northeast Asia. U.S. Geological Survey, Reston, pp 99-165

Dewey JF (1977) Suture zone complexities: a review. Tectonophysics 40:53-67

Grayver AV (2015) Parallel three-dimensional magnetotelluric inversion using adaptive finite-element method. Geophys J Int 202:584-603

Guy A, Schulmann K, Munschy M, Miege JM, Edel JB, Lexa O, Fairhead D (2014) Geophysical constraints for terrane boundaries in southern Mongolia. J Geophys Res Solid Earth 119:7966-7991

Guy A, Schulman K, Janoušek V, Stipska P, Armstrong R, Belousova E, Dolgopolova A, Seltmann R, Lexa O, Jiang Y, Hanžl P (2015) Geophysical and geochemical nature of relaminated arc-derived lower crust underneath oceanic domain in southern Mongolia. Tectonics 34:1030-1053

Ho T, Priestley K, Debayle E (2016) A global horizontal shear velocity model of the upper mantle from multimode love wave measurements. Geophys J Int 207:542-561

Jiang YD, Schulmann K, Kröner A, Sun M, Lexa O, Janoušek V, Hanžl P (2017) Neoproterozoic-early Paleozoic peri-Pacific accretionary evolution of the Mongolian collage system: insights from geochemical and U-Pb zircon data from the Ordovician sedimentary wedge in the Mongolian Altai. Tectonics 36:2305-2331

Kalscheuer T, Juanatey MDÁG, Meqbel N, Pedersen LB (2010) Non-linear model error and resolution properties from two-dimensional single and joint inversions of direct current resistivity and radiomagnetotelluric data. Geophys J Int 182:1174-1188

Käufl JS, Grayver AV, Kuvshinov AV (2018) Topographic distortions of magnetotelluric transfer functions: a high-resolution 3D modelling study using real elevation data. Geophys J Int 215:1943-1961
Käufl JS, Grayver AV, Comeau MJ, Kuvshinov AV, Becken M, Batmagnai E, Demberel S (2020) Magnetotelluric multiscale 3-D inversion reveals crustal and upper mantle structure beneath the Hangai and Gobi-Altai region in Mongolia. Geophys J Int 221 (in press)

Key K (2016) MARE2DEM: a 2D inversion code for controlled-source electromagnetic and magnetotelluric data. Geophys J Int 207:571-588

Kovach V, Salnikova E, Wang K, Jahn B, Chiu H, Reznitskiy L, Kotov A, lizuka Y, Chung $S$ (2013) Zircon ages and $\mathrm{H}$ f isotopic constraints on sources of clastic metasediments of the Slyudyansky high-grade complex, southeastern Siberia: implication for continental growth and evolution of the Central Asian Orogenic Belt. J Asian Earth Sci 62:18-36

Kröner A, Lehmann J, Schulmann K, Demoux A, Lexa O, Tomurhuu D, Štípská P, Otgonbator D, Liu D, Wingate M (2010) Lithostratigraphic and geochronological constraints on the evolution of the Central Asian Orogenic Belt in SW Mongolia: early Paleozoic rifting followed by Late Paleozoic accretion. Am J Sci 310:523-574

Li CF, Ly Y, Wang J (2017) A global reference model of Curie-point depths based on EMAG2. Sci Rep 7:45129

Meltzer A, Stachnik JC, Sodnomsambuu D, Munkhuu U, Tsagaan B, Dashdondog M, Russo R (2019) The Central Mongolia seismic experiment: multiple applications of temporary broadband seismic arrays. Seismol Res Lett 90:1364-1376

Muñoz G, Ritter O (2013) Pseudo-remote reference processing of magnetotelluric data: a fast and efficient data acquisition scheme for local arrays. Geophys Prospect 61:300-316

Petiau G (2000) Second generation of lead-lead chloride electrodes for geophysical applications. Pure Appl Geophys 157:351-382

Petit C, Tiberi C, Deschamps A, Déverchère J (2008) Teleseismic traveltimes, topography and the lithospheric structure across central Mongolia. Geophys Res Lett 35:1-5

Rizza M, Ritz JF, Prentice C, Vassalo R, Braucher R (2015) Earthquake geology of the Bulnay Fault (Mongolia). Bull Seismol Soc Am 105:72-93

Rung-Arunwan T, Siripunvaraporn W, Utada H (2016) On the Berdichevsky average. Phys Earth Planet Interiors 253:1-4

Sheldrick TC, Barry TL, Van Hinsbergen DJJ, Kempton P (2018) Constraining lithospheric removal and asthenospheric input to melts in Central Asia: a geochemical study of Triassic to Cretaceous magmatic rocks in the Gobi Altai (Mongolia). Lithos 296-299:297-315

Smith J (1995) Understanding telluric distortion matrices. Geophys J Int 122:219-226

Styron R (2018) GEM foundation global active faults project (GEM-GAF). Zenodo. http://doi.org/10.5281/zenodo.1404388

Türkoğlu E, Unsworth M, Çağlar I, Tuncer V, Avşar Ü (2008) Lithospheric structure of the Arabia-Eurasia collision zone in eastern Anatolia: magnetotelluric evidence for widespread weakening by fluids? Geology 36:619-622

Unsworth MJ, Rondenay S (2012) Mapping the distribution of fluids in the crust and lithospheric mantle utilizing geophysical methods. In: Harlov DE, Austrheim $\mathrm{H}$ (eds) Metasomatism and the chemical transformation of rock. Lecture notes in earth system sciences. Springer, Berlin, pp 535-598

Van der Voo R, van Hinsbergen DJJ, Domeier M, Spakman W, TorsvikTH (2015) Latest Jurassic-earliest Cretaceous closure of the Mongol-Okhotsk Ocean: a paleomagnetic and seismological-tomographic analysis. Geol Soc Am Spec Pap 513:589-606

Walker RT, Nissen E, Molor E, Bayasgalan A (2007) Reinterpretation of the active faulting in central Mongolia. Geology 35:759-762

Weidelt P (1972) The inverse problem of geomagnetic induction. J Geophys 38:257-289

Xiao W, Windley BF, Sun S, Li J, Huang B, Han C, Yuan C, Sun M, Chen H (2015) A tale of amalgamation of three permo-triassic collage systems in Central Asia: oroclines, sutures, and terminal accretion. Ann Rev Earth Planet Sci 43:477-507

Yin A (2010) Cenozoic evolution of Asia: a preliminary synthesis. Tectonophysics 488:293-325

\section{Publisher's Note}

Springer Nature remains neutral with regard to jurisdictional claims in published maps and institutional affiliations. 